\title{
Endoscopic coronary artery bypass grafting-The first steps on a long journey
}

Ralph J. Damiano, Jr, MD

From the Division of Cardiothoracic Surgery, Barnes-Jewish Hospital, St Louis, Mo.

Received for publication March 29, 2000; accepted for publication June 16, 2000.

Address for reprints: Ralph J. Damiano, Jr, MD, Chief, Cardiac Surgery, Division of Cardiothoracic Surgery, 1 Barnes-Jewish Hospital Plaza, Suite 3108 Queeny Tower, Campus Box 8234, St Louis, MO 63110.

J Thorac Cardiovasc Surg 2003;125:S64-5 Originally published in J Thorac Cardiovasc Surg 2000;120:806-7.

Copyright $(\odot) 2003$ by The American Association for Thoracic Surgery

$0022-5223 / 2003 \$ 30.00+0$

doi: $10.1067 / \mathrm{mtc} .2003 .228$

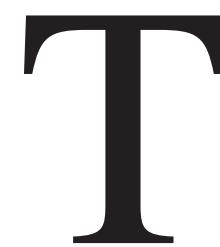

he penultimate goal of minimally invasive coronary revascularization would be a procedure that combines the superior outcomes of traditional open-chest coronary artery bypass grafting $(\mathrm{CABG})$ with the invasiveness of angioplasty. In this issue of the Journal, two groups report on a significant step in that direction by performing endoscopic procedures on the beating heart. ${ }^{1,2}$ They are to be congratulated for their pioneering work and this important achievement in the field of minimally invasive CABG.

There has been rapid progress in the development of endoscopic CABG over the past year. In a short period of time, endoscopic CABG has gone from the realm of speculation to a clinical reality. This has been enabled by the use of sophisticated robotic microsurgical systems. The robotic systems consist of three principal components: a surgeon console, a computer control system, and robotic manipulators. The surgeon sits at the console and grasps specially designed instrument handles. The surgeon's motions are relayed to a computer processor, which digitizes his or her hand motions. The digitized information from the computer control system is relayed in real time to robotic manipulators, which are attached to the operating room table. These manipulators hold the endoscopic instrument tips, which are inserted into the patient through small ports.

The unique power of these systems is the digital interface between the surgeon and the instrument tips. This allows for the surgeon's hand motions, now in a digital format, to be precisely manipulated and filtered by the system's software. Because high-frequency signals are eliminated, surgical tremor is removed. Moreover, this interface allows for motion scaling. Easy-to-perform macroscopic movements at the console are scaled down to a microscopic scale inside the patient, thus enhancing dexterity. Finally, these systems remove the nonintuitive motion of traditional endoscopic instruments. An endoscopic instrument has a fixed pivot point at its entry site into the chest wall. When the instrument handle is moved to the left, the tip goes in the opposite direction. This "nonintuitive" movement adds a level of difficulty to the performance of microvascular anastomoses. With robotic microsurgical systems, the instrument handle is separated from the tip by the computer control system. Thus, this drawback of endoscopy can be eliminated, restoring the intuitive movements of open surgery in which the instrument handle and tip always move in the same direction.

The two robotic microsurgical systems that presently are under clinical investigation are the da Vinci System by Intuitive Surgical, Inc (Mountain View, Calif) and the Zeus Microsurgical System by Computer Motion, Inc (Goleta, Calif). Both systems have been used to perform endoscopic CABG. ${ }^{1-4}$ The first prospective trial of this technology was recently reported and confirmed the safety and efficacy of this approach in selected patients. ${ }^{5}$ With the use of endoscopic techniques, it has been possible to achieve excellent graft patency in selected patients.

These early reports represent the beginning of a new era in our field. Computer assistance clearly enhances surgical ability. For the first time, surgeons are freed from the shackles of their own physical limitations. As this technology matures, computer enhancement of our hand motions should allow us not only to perform our current procedures with more agility but also to significantly expand our surgical 
horizons. In the future, our surgical ability may be limited only by the power of our imagination.

Although the era of computer-assisted cardiac surgery has exciting potential, it is important to clearly define the present state of the art. The procedure described by both Kappert and Boyd's groups is the world's most expensive, least applicable, and most technically difficult minimally invasive $\mathrm{CABG}$ procedure. A significant amount of development work needs to be done to evolve endoscopic CABG from a technical tour de force into a commonly performed procedure. We must remember that patients undergoing these early endoscopic procedures have been carefully selected. It is important to choose patients with favorable chest wall anatomy. Obese patients should be avoided and can make endoscopic internal thoracic artery dissection difficult. Moreover, the robotic systems presently in use have no force feedback. Because of this, it is not advisable to operate on calcified or diseased coronary arteries. Intraoperative times, although improving, are still significantly longer than traditional minimally invasive $\mathrm{CABG}$ procedures. Most important, these robotic systems are extraordinarily expensive. It is fair to say that there is currently little clinical value added with the use of these systems.

These reports represent the first steps on a long journey. Robotically assisted cardiac surgery remains in the arena of clinical investigation. The procedures remain difficult and time consuming. They require superb surgical judgment and careful patient selection, along with well-developed endoscopic skills. Widespread application of this technology will require us to surmount numerous surgical and technical challenges. These challenges include developing ways to facilitate the anastomosis, improve operative choreography, enhance the margin for error, and widen the applicability of these techniques to patients with multiple vessel disease. Most important, we will need to carefully evaluate these procedures in multicenter prospective trials to define their efficacy and clinical value.

In summary, these groups are to be congratulated for their surgical achievements. Computer assistance holds a tremendous potential to enable cardiac surgeons to perform truly minimally invasive procedures. Both of these reports give us a glimpse into what promises to be an exciting future. The integration of computers into the operating room and our surgical practice over the next decade will have a revolutionary impact on our specialty, resulting in a significant expansion of our surgical ability and a marked reduction in the morbidity of cardiac surgery.

\section{References}

1. Kappert V, Cichon R, Schneider J, Gulielmos V, Tugtekin SM, Matschke K, et al. Closed-chest coronary artery surgery on the beating heart with the use of a robotic system. $J$ Thorac Cardiovasc Surg. 2000:120:809-11.

2. Boyd WD, Rayman R, Desai ND, Menkis AH, Dobkowski W, Ganapathy $\mathrm{S}$, et al. Closed-chest coronary artery bypass grafting on the beating heart with the use of a computer-enhanced surgical robotic system. J Thorac Cardiovasc Surg. 2000:120:807-9.

3. Mohr FW, Falk V, Diegeler A, Autschback R. Computer-enhanced coronary artery bypass surgery. J Thorac Cardiovasc Surg. 1999;117: 1212-5.

4. Reichenspurner H, Damiano RJ, Mack M, Boehm DM, Gulbins H, Meisner B, et al. Experimental and first clinical use of the voicecontrolled and computer-assisted surgical system Zeus for endoscopic coronary artery bypass grafting. J Thorac Cardiovasc Surg. 1999;118: 11-6.

5. Damiano RJ Jr, Ehrman WJ, Ducko CT, Tabaie HA, Stephenson ER, Kingsley CP, et al. Initial United States clinical trial of robotically assisted endoscopic coronary artery bypass grafting. $J$ Thorac Cardiovasc Surg. 2000;119:77-82. 